\title{
SHRINKAGE AND THERMAL EFFECTS IN R/C FLAT PLATE AND RAFT FOUNDATION
}

\author{
Salah E. El-Metwally ${ }^{1}$, Mohamed E. El-Zoughiby ${ }^{2}$, Reda M. Elgarayhi ${ }^{3}$ \\ ${ }^{1}$ Prof. of Structural Concrete, ${ }^{2}$ Associate Prof. of Structural Concrete, ${ }^{3}$ Graduate Student \\ Structural Engineering Department, Mansoura University, El-Mansoura, Egypt
}

\begin{abstract}
In this study, the effect of shrinkage and temperature variation on the behavior of long span reinforced concrete flat plate system and raft foundation supported directly on soil or piles, has been examined via the nonlinear finite element analysis. In the analysis, shrinkage has been considered as a drop of temperature of $30^{\circ} \mathrm{C}$ for the flat plate system and of $20^{\circ} \mathrm{C}$ for the raft foundation. A change of temperature of uniform profile and of nonlinear gradient have been considered. The analysis accounted for material nonlinearity and it has been performed for all possible load combinations.

The results of analysis revealed that material nonlinearity plays a major role in the response of the structure for temperature and shrinkage effects since its presence remarkably reduced the adverse effect of the two factors. Shrinkage and temperature variation had more significant effect on slabs than on rafts. Their effect on concrete stresses was not critical in slabs and had no significance in rafts. On the other hand, such effect on steel reinforcement was noticeable in rafts and significant in slabs. This led to the conclusion that the effect of both temperature variation and shrinkage can be accommodated by additional reinforcement. In slabs, for an accurate assessment of deflection, it is important to account for both factors in the analysis.
\end{abstract}

Keywords: Reinforced Concrete; Flat plate; Shrinkage; Temperature changes; Nonlinear Finite Element Analysis; ABAQUS.

\section{Introduction}

If a reinforced concrete structure in any way is hindered to deform due to volume changes, shrinkage, temperature variation and creep, restraining forces will appear. The prevented deformation results in tensile or compressive stresses, which will result in cracking if the concrete tensile strength is reached. Currently, in most design codes, the restraining effect due to concrete volume changes should be considered in combination with other loads (such as gravity and lateral) if their presence adversely affects the structural safety. 
Salah E. El-Metwally /et al /Engineering Research Journal 163 (September 2019) C1- C21 
Restraint of movements associated with volume changes can cause significant internal forces in a structure. Several strategies can be followed to accommodate movements; e.g., expansion joints and construction closure strips. Nevertheless, such measures have negative effect on the structure performance with regard to durability, ease of construction, ..., etc. For better performance of long span structures, accounting for restraint stresses, without having to introduce expansion joints or closure strips, would be the best option.

In this study, the effect of shrinkage and temperature variation on the behavior of long span flat plate system and raft foundation is examined. The nonlinear finite element, with the aid of the software ABAQUS (2016), is utilized in performing the analysis. The analysis accounts for material nonlinearity and it is performed for all possible load combinations.

\section{Shrinkage and Thermal Effects}

Reinforced concrete structures undergo three main types of volume changes, shrinkage, creep, and thermal effects (expansion or contraction). These volume changes, if restrained, may cause stresses, cracking, or deflections, which affect the in-service behavior of the structure.

Shrinkage: Shrinkage strains depend on many factors such as the concrete quality, the volume to surface ratio of the structural member, the relative humidity, ... etc. Therefore, it is quite difficult to put a fixed figure of shrinkage strain into the analysis. For normal conditions, the final shrinkage strain according to the ACI Committee 209 (1997) and the Egyptian Code, ECP 203 (2017), may vary between $200 \times 10^{-6}$ and higher than $300 \times 10^{-6}$. Since this study is qualitative, a value of shrinkage strain of $300 \times 10^{-6}$ has been assumed for the flat plate system and $200 \times 10^{-6}$ for the raft foundation.

Thermal effects: Changes in temperature can produce stresses in concrete structures of the same order of magnitude as the dead or live loads. However, the stresses due to temperature changes are produced only when the thermal expansion or contraction is restrained. High tensile stresses due to temperature variation often result in cracking of concrete; once this occurs, the restraint to thermal expansion or contraction of concrete is gradually released and its stresses are reduced. Thermal stresses can be reduced and the risk of damage caused by temperature changes can be eliminated by provision of expansion joints and sufficient well distributed reinforcements. For this reason and because of the complexity of the problem, many structures are designed by empirical rules (Ghali, et al., 2006).

The temperature distribution over cross-section varies with time and depends upon several variables such as the geometry of the cross-section, thermal conductivity, specific heat and density of the material, nature and color of the exposed surfaces, expressed in terms of solar radiation absorptivity, emissivity and convection coefficients, orientation of the structure axis, time of the day and the season, diurnal variations of ambient air temperature and wind speed and degree of cloudiness and turbidity of the atmosphere. 
Various codes give different thermal gradients that must be considered in thermal stress analysis. Some codes take temperature gradients uniform over the cross section and other codes take it linear or nonlinear. The Egyptian Code for loads, ECP 201 (2012), requires that the change in temperature be taken $30^{\circ} \mathrm{C}$ for steel and composite structures and $20^{\circ} \mathrm{C}$ for concrete structures. In this study, both uniform and nonlinear temperature gradients are considered.

As a result of restrained stresses due to thermal loads, two types of thermal stress develop: primary thermal stresses (self-equilibrating) and continuity thermal stresses. Primary thermal stresses are induced in a section due to nonlinear thermal gradient only because each fiber being attached to adjacent fibers is not free to obtain the full expansion due to temperature changes. In other words, if each fiber was free to expand, the resulting strain is of nonlinear distribution as the temperature gradient, but because plane sections tend to remain plane, the actual strain distribution has a linear form. The difference between the nonlinear strain due to temperature and the cross section linear strain distribution represents expansion or contraction which is restrained by the selfequilibrating stresses, Fig. 1a.

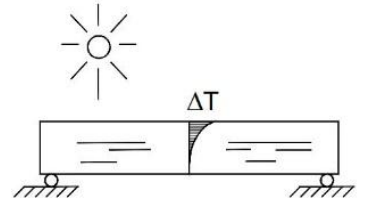

(a) Unrestrained beam

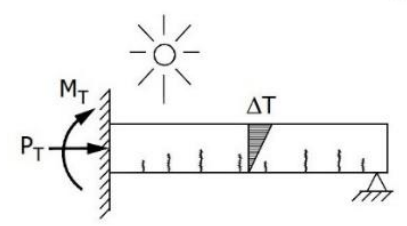

(b) Restrained beam

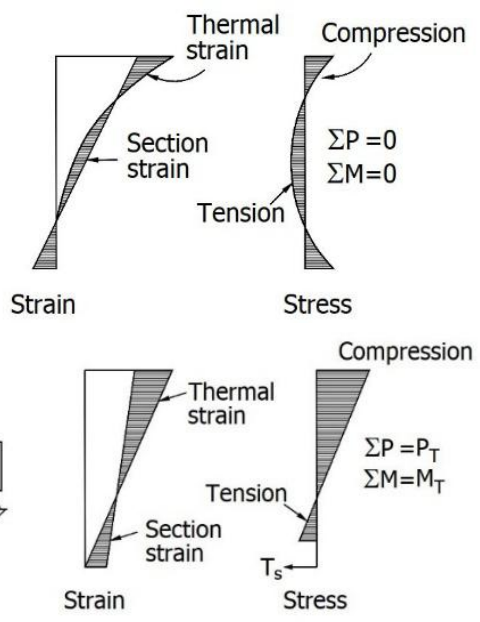

(Ghali, et al., 2006)Fig. 1 Thermal stresses: (a) primary stress, and (b) continuity stress

Continuity thermal stresses, are the stresses induced in indeterminate structures as a result of restrained member deflections and rotations arising from thermal deformations. In most instances, continuity thermal stresses are of greater magnitude than primary thermal stresses. The thermal stresses induced in reinforced concrete structures are unlike most other mechanical stresses in that they tend to be self-relieving to some degree, Fig. 1b (Ghali, et al., 2006). Logically, no stresses exist when the change in temperature varies uniformly or linearly over cross-section of a determinate structure because expansion and contraction are unrestrained.

\section{Material and Finite Element Modeling}

Concrete: Concrete smeared cracking model is adopted in this study since it provides a general capability for modeling concrete in all types of structures, including beams, trusses, shells, and solids and can be used with rebar to model concrete reinforcement, Fig. 
2 (ABAQUS, 2016). This model needs some parameters to be defined such as compressive stress-plastic strain curve, tension stiffening, failure ratios, and shear retention in addition to basic properties such as the modulus of elasticity, Poison's ratio, density and thermal properties.

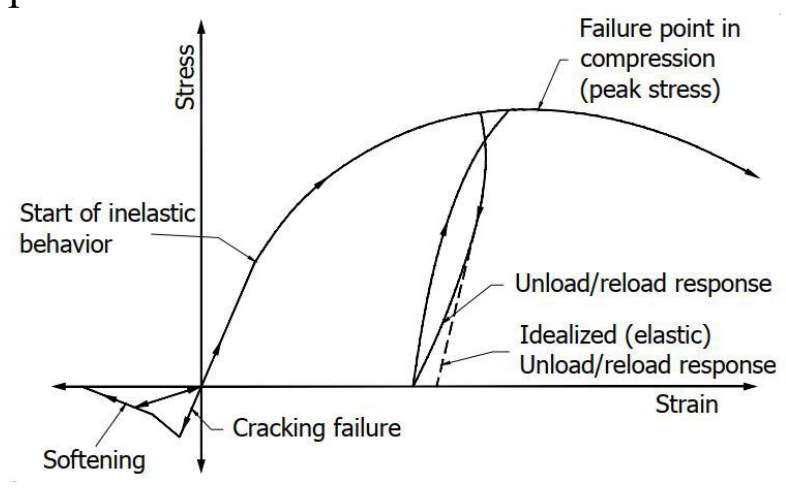

Fig. 2 Uniaxial behavior of plain concrete

Basic properties: In this study, the cube concrete strength is assumed as, $f_{c u}=30 \mathrm{~N} /$ $\mathrm{mm}^{2}$, the elastic modulus of concrete, $E_{c}$, is assumed constant which means that it does not vary with the temperature variation and constant for all parts of the model. It is calculated according to the Egyptian Code ECP $203(2017)$ as, $E_{c}=4400 \sqrt{f_{c u}} \mathrm{~N} / \mathrm{mm}^{2}$. The Poison's ratio, $v=0.20$ and the concrete density, $\gamma_{c}=25 \mathrm{kN} / \mathrm{mm}^{3}$.

The uniaxial stress-strain relation: The modified Hognestad curve (Chaudhari and Chakrabarti, 2012) shown in Fig. 3, is adopted in this study, which is expressed as:

$$
\begin{array}{ll}
\frac{\sigma}{\sigma_{u}}=2 \frac{\varepsilon}{\varepsilon_{o}}\left(1-\frac{\varepsilon}{2 \varepsilon_{o}}\right) & 0<\varepsilon<\varepsilon_{o} \\
\frac{\sigma}{\sigma_{u}}=1-0.15\left(\frac{\varepsilon-\varepsilon_{o}}{\varepsilon_{u}-\varepsilon_{o}}\right) & \varepsilon_{o}<\varepsilon<\varepsilon_{u} \\
\varepsilon=\varepsilon_{e}+\varepsilon_{p}, \varepsilon_{e}=\sigma / E_{c} &
\end{array}
$$

where $\varepsilon$ is the strain, $\varepsilon_{e}$ is the elastic strain, $\varepsilon_{p}$ is the plastic strain, $E_{c}$ is the modulus of elasticity, $\varepsilon_{o}$ is the strain corresponding to the peak stress and is equal to $0.002, \varepsilon_{u}$ is the strain at failure and is equal to $0.0035, \sigma$ is the stress and $\sigma_{u}$ is the peak stress.

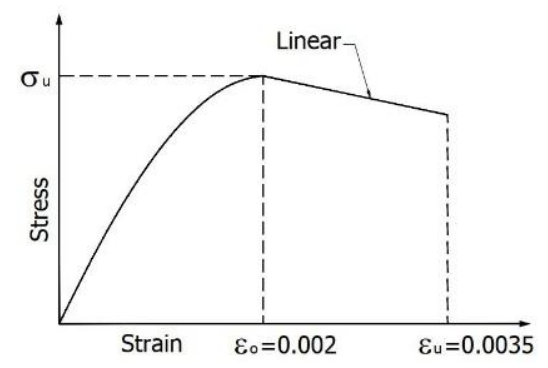

Fig. 3 Modified Hognestad stress-strain curve (Chaudhari and Chakrabarti, 2012)

Tension stiffening: It is specified by means of a post-failure stress-strain relation as shown in Fig. 4. It is defined as the plastic strain at which the cracking stresses causing tensile 
failure of the concrete reduce to zero. This reduction of tensile cracking stresses with plastic strain can be expressed by linear or multi-linear curve. There is a direct relationship between the stiffness degradation and stress drop after cracking (Alih and Khelil, 2012).

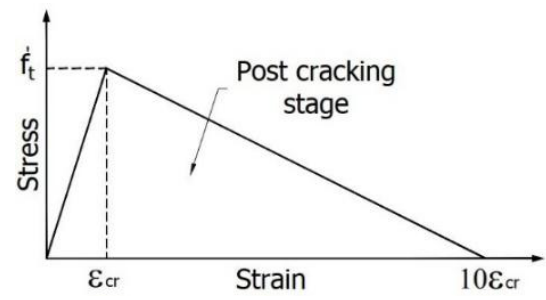

Fig. 4 Tension stiffening model of concrete (Alih and Khelil, 2012)

The selection of tension stiffening parameters is important in $A B A Q U S$ since, greater tension stiffening makes it easier to obtain numerical solutions. Otherwise local cracking failure in the concrete will take place, thus introducing temporarily unstable behavior in the overall response of the model. In this study, tension stiffening is taken as linear relationship and the total strain that corresponds to zero tensile strength is assumed to be ten times the crack strain of plain concrete. Tension stiffening is also utilized to model the bond between steel bars and concrete (Alih and Khelil, 2012) and (Chaudhari and Chakrabarti, 2012).

Failure ratios: To define the failure surface, four failure ratios can be specified as shown in Fig. 5.

- Ratio of the ultimate biaxial compressive stress to the uniaxial compressive ultimate stress, a value of 1.16 is specified;

- Absolute value of the ratio of uniaxial tensile stress at failure to the uniaxial compressive stress at failure, a value of 0.08 is used;

- Ratio of the magnitude of a principal component of plastic strain at ultimate stress in biaxial compression to the plastic strain at ultimate stress in uniaxial compression, a value of 1.28 is used; and

- Ratio of the tensile principal stress value at the inplane cracking stress, when the other nonzero principal stress component is at the ultimate compressive stress value, to the tensile cracking stress under uniaxial tension, a value of 0.333 is assumed (ABAQUS, 2016).

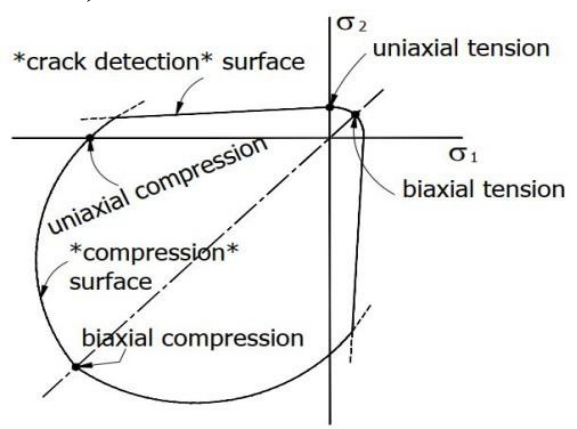

Fig. 5 Yield and failure surfaces in plane stress 
Shear retention: In this study, a full shear retention is defined which means that shear response is unaffected by cracking; the default of the program (ABAQUS, 2016 and Chaudhari and Chakrabarti, 2012).

Thermal properties: Assuming the concrete properties are constant with temperature changes, it is assumed that the coefficient of thermal expansion, $\alpha$, is equal to $1 \times 10^{-5} / \mathrm{C}^{\circ}$, thermal conductivity, $k$, is equal to $1.0 \mathrm{~W} / \mathrm{mK}$, and specific heat, $c$, is equal to $1000 \mathrm{~J} / \mathrm{kg}$. $\mathrm{K}, k$ and $c$ have no effect on this analysis because temperature gradients are defined as a boundary condition at every node along the cross-section thickness.

Adopted Element in ABAQUS: The continuum solid element used to model concrete C3D8RT, which is an 8-node thermally coupled brick-hexahedral, trilinear displacement and temperature, reduced integration, hourglass control, is used to model concrete for 3D stress analysis under mechanical loads and thermal effects. The element C3D8RT has 4 degrees of freedom at corner nodes, three transitional degrees of freedom in $\mathrm{x}, \mathrm{y}$, and $\mathrm{z}$ directions and one for temperature.

Reinforcing steel: It is assumed to be elastic-perfectly plastic material in both tension and compression, with a modulus of elasticity $E_{s}=2 \times 10^{5} \mathrm{~N} / \mathrm{mm}^{2}$, yield stress $\mathrm{f}_{\mathrm{y}}=360 \mathrm{~N} /$ $\mathrm{mm}^{2}$, and Poison's ratio $v=0.30$. The coefficient of thermal expansion, $\alpha$, is equal to $1 \times 10^{-5} / \mathrm{C}^{\mathrm{o}}$, thermal conductivity, $k$, is equal to $45 \mathrm{~W} / \mathrm{mK}$, and specific heat, $c$, is equal to $480 \mathrm{~J} / \mathrm{kg}$. K, $k$ and $c$ have no effect on this analysis because temperature gradients are defined as a boundary condition at every node along the cross-section thickness. Adopted Elements in ABAQUS: In this study, reinforcement has been modeled as surface element containing rebars, in the form of one or multiple layers. For each layer, rebar properties including the cross-sectional area of each bar, rebar material, rebar orientation angle with respect to the local coordinate system of the surface element, and the spacing between bars, must be specified. The rebar layer(s) must be embedded in the concrete as discussed before. This method is suitable for slabs and rafts. Surface element is defined as a membrane in space with zero thickness; it has no inherent stiffness and may be used to define a rebar layer. The surface element which is used to model reinforcement in the concrete is called SFM3D4R which is a 4-node, membrane like, quadrilateral surface element and reduced integration. Each corner node of the element has three transitional degrees of freedoms in the $\mathrm{x}, \mathrm{y}$ and $\mathrm{z}$ directions (ABAQUS, 2016).

Bond between concrete and reinforcement: In this analysis, a full bond between concrete and reinforcement is assumed. This assumption is implemented by the use of a constraint called embedded element (ABAQUS, 2016). Reinforcement is embedded into the host elements, concrete, so that all embedded element's nodes have the same translational degrees of freedom as the concrete host element's nodes.

\section{Verification}

In order to verify the analysis with $A B A Q U S$ program, a simple concrete cube of size $150 \mathrm{~mm}$ is modeled and analyzed with $A B A Q U S$ using the C3D8R element. The material properties are as discussed before in this section, with cube strength $f_{c u}=30 M P a$. The 
center of the cube at the bottom surface is prevented from translation in the $\mathrm{x}, \mathrm{y}$ and $\mathrm{z}$ directions and all other points of this surface are prevented from translation in $\mathrm{z}$ direction. The load is applied gradually through the displacement control approach at the top surface of the cube, as uniform displacement and increases up to the failure displacement. In this example, the ratio of uniaxial tensile stress at failure to the uniaxial compressive stress at failure $=0.08$.

\section{At compression failure,}

$$
\varepsilon_{u}=-0.0035
$$

$\therefore$ displacement load $=-0.0035 \times 150=-0.525 \mathrm{~mm}$

\section{At tension failure,}

$$
\begin{aligned}
& f_{t}=0.08 \times f_{c u}=0.08 \times 30=2.40 \\
& \varepsilon_{c r}=f_{t} / E_{c}=2.4 / 24100 \cong 0.0001 \\
& \varepsilon_{u t}=10 \times \varepsilon_{c r}=0.001 \\
& \therefore \text { displacement load }=0.001 \times 150=0.15 \mathrm{~mm}
\end{aligned}
$$

The stress-strain curves of the concrete material model and the obtained results at the centroid of the cube are illustrated in Fig. 6 for the two cases of compression and tension. From the obtained results, it is obvious that the predictions of the finite element analysis using $A B A Q U S$ are very satisfactory.

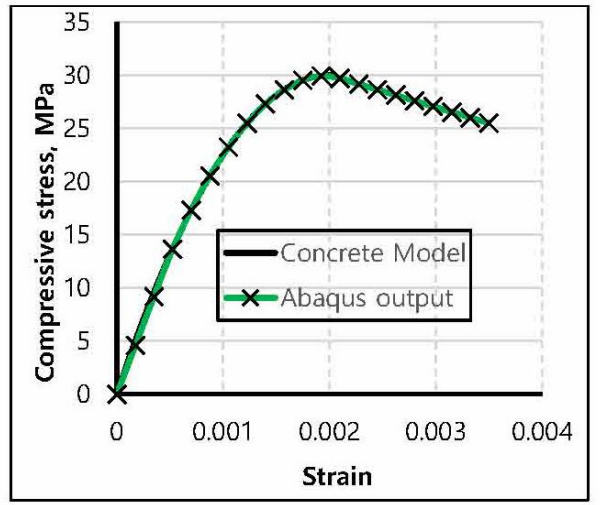

(a) Compression

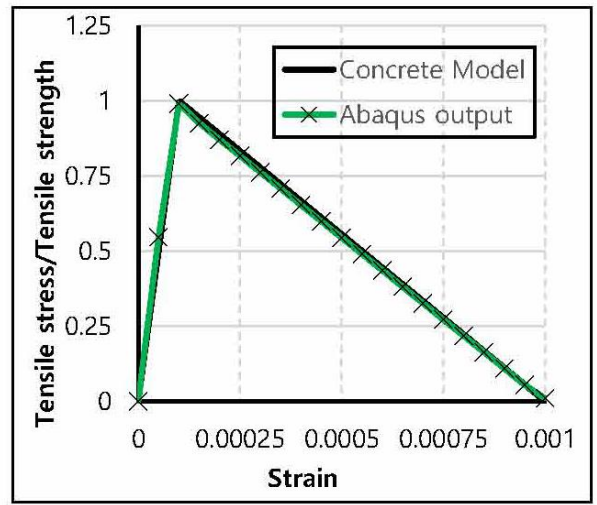

(b) Tension

Fig. 6 Results in the standard cube

\section{Flat Plate - Case Study}

One model of flat plate designated as ST1 is presented in this paper. The model is analyzed under different temperature gradients plus shrinkage, where shrinkage is introduced as a drop-in temperature of $30^{\circ} \mathrm{C}$. The temperature is assumed to vary only within the slab thickness and to be constant all over the slab surface. The analysis has been carried out for different load combinations.

Fig. 7 shows the geometry of the slab ST1 which consists of one-story flat plate of thickness $250 \mathrm{~mm}$ supported by square columns of similar dimensions of $500 \times 500 \mathrm{~mm}$ 
with clear height equal to $4 \mathrm{~m}$. In the $\mathrm{x}$-direction there are seven spans, each span is equal to $8.0 \mathrm{~m}$ from the centerline of columns, so the total slab length in this direction is equal to $56.5 \mathrm{~m}$. In the z-direction there are five spans, each span is equal to $8.0 \mathrm{~m}$ from the centerline of columns, so the total slab length in this direction is equal to $40.5 \mathrm{~m}$.

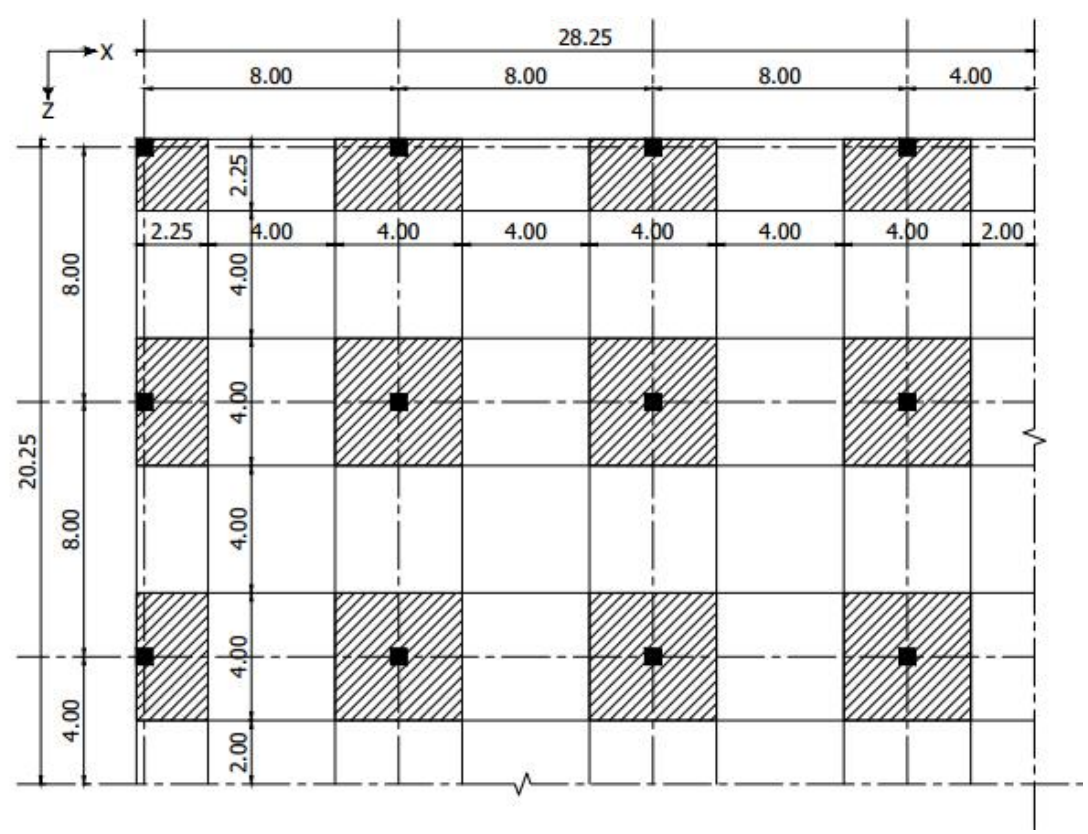

Fig. 7 One quarter dimensions of a slab model ST1

The slab is divided into column and middle strips, as shown in Fig. 7, and is reinforced with bottom and top steel mesh of $\Phi 10-150 \mathrm{~mm}$ in both directions. In addition, the slab has additional top reinforcement at the intersections of column strips, which makes the total top reinforcement equivalent to $\Phi 18-150 \mathrm{~mm}$ in both directions at these zones. The top and bottom concrete covers equal to $25 \mathrm{~mm}$ measured from the slab exterior fibers to the center of the rebars, where the reinforcement has been modeled as one surface layer.

The slab is carrying a total working load equal to $12.75 \mathrm{kN} / \mathrm{m}^{2}$ (covering the own weight, the superimposed dead load and live load) applied at its top surface as a uniform pressure. In addition to the gravity loads, the slab is assumed to carry thermal loads in the form of temperature gradients which are uniform, nonlinear gradients and shrinkage as a drop-in temperature as shown in Fig. 8. Thus, there are eleven loading cases of nonlinear analyses, as given in the following:

Case $\boldsymbol{A}$ - vertical loads only.

Case B - vertical loads + uniform temperature gradient (T1).

Case $\boldsymbol{C}$ - vertical loads - uniform temperature gradient (T1).

Case D - vertical loads + nonlinear temperature gradient (T2).

Case $\boldsymbol{E}$ - vertical loads - nonlinear temperature gradient (T2).

Case $\boldsymbol{S} \boldsymbol{h}$ - shrinkage as a drop-in temperature (T3) only.

Case $\boldsymbol{A} \boldsymbol{S h}$ - case A + shrinkage (T3).

Case BSh - case B + shrinkage (T3).

Case CSh - case C + shrinkage (T3). 
Case DSh - case D + shrinkage (T3).

Case $\boldsymbol{E S h}$ - case E + shrinkage (T3).

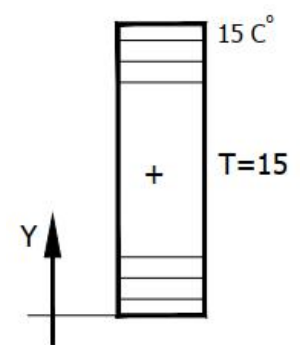

(a) Uniform gradient
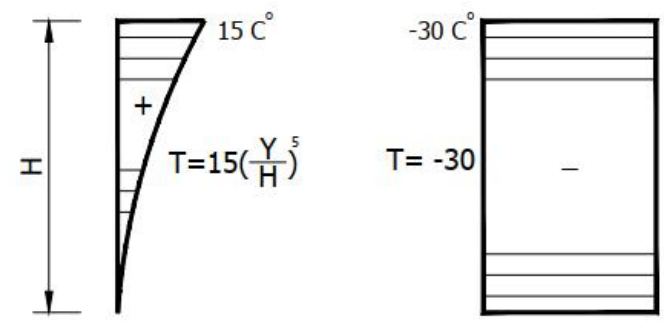

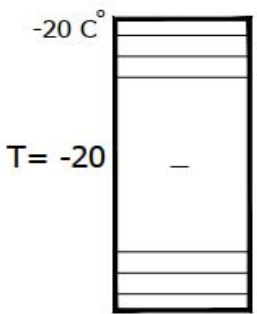

(b) Nonlinear gradient (c) Shrinkage in slab (d) Shrinkage in raft

Fig. 8 Positive temperature gradients and shrinkage

All columns are assumed to be restrained at their bases $\left(U_{x}, U_{y}\right.$ and $\left.U_{z}=0.0\right)$. There are two axes of symmetry in the $\mathrm{x}$ - and $\mathrm{z}$-directions (the boundary conditions along the $\mathrm{x}$ axis are $\mathrm{U}_{\mathrm{x}}, \mathrm{UR}_{\mathrm{y}}$ and $\mathrm{UR}_{\mathrm{z}}=0.0$ and along the $\mathrm{z}$-axis are $\mathrm{U}_{\mathrm{z}}, \mathrm{UR}_{\mathrm{x}}$ and $\mathrm{UR}_{\mathrm{y}}=0.0$ ) so that one quarter of the model only is analyzed. Abaqus/Explicit has been adopted in the analysis and modeling.

\section{Results and Comments}

Due to the large size of the results obtained from the finite element analysis, only some selected results of slab ST1 are presented in Figs. 9 to 13. From the obtained results, the values given in Tables 1 to 5 can be compared; the results are normalized to that of case A (case of gravity loads only).
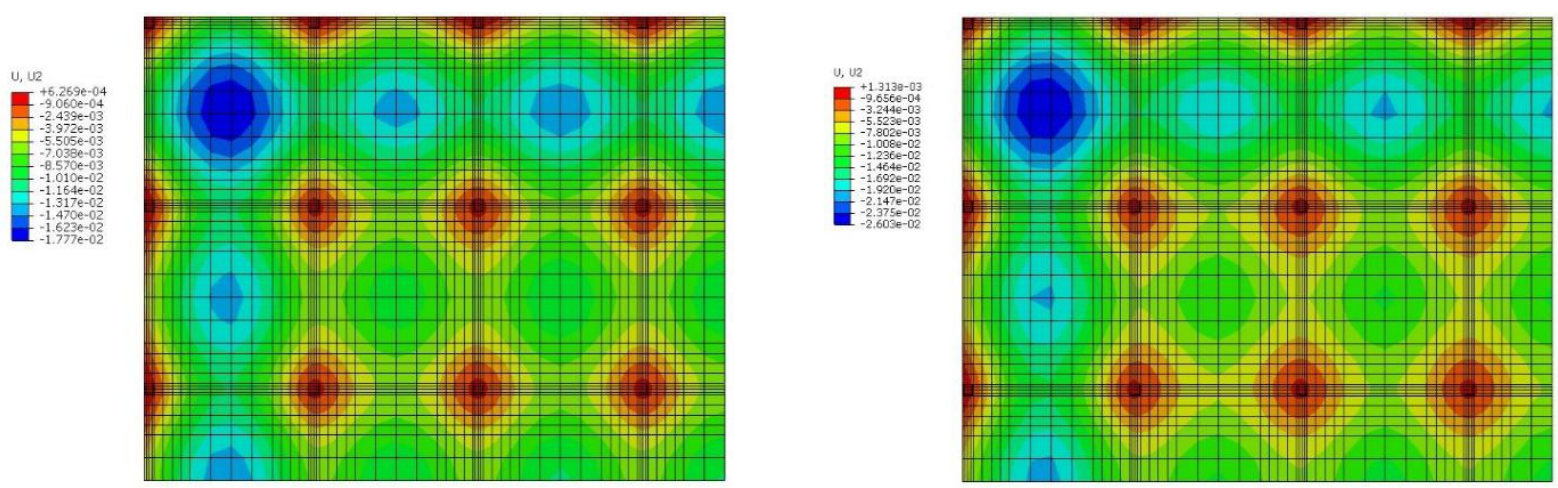

Fig. 9 Deflections of ST1 model for cases A and DSh
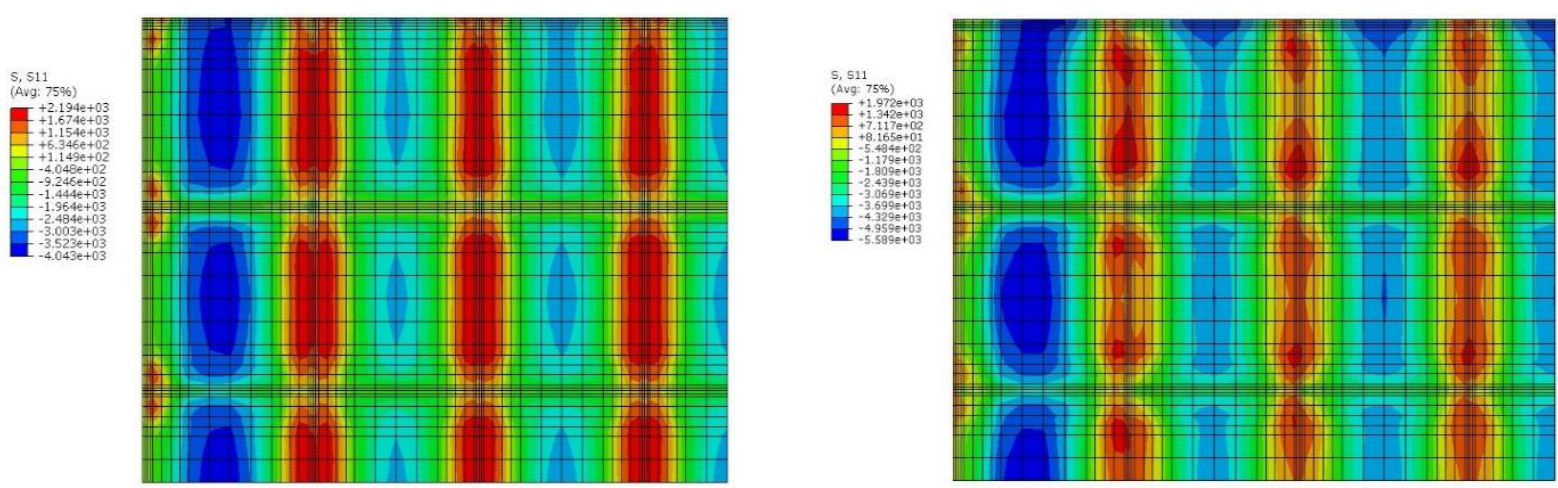

Fig. 10 Stresses in top surface, x-direction of ST1 model for cases A and DSh 

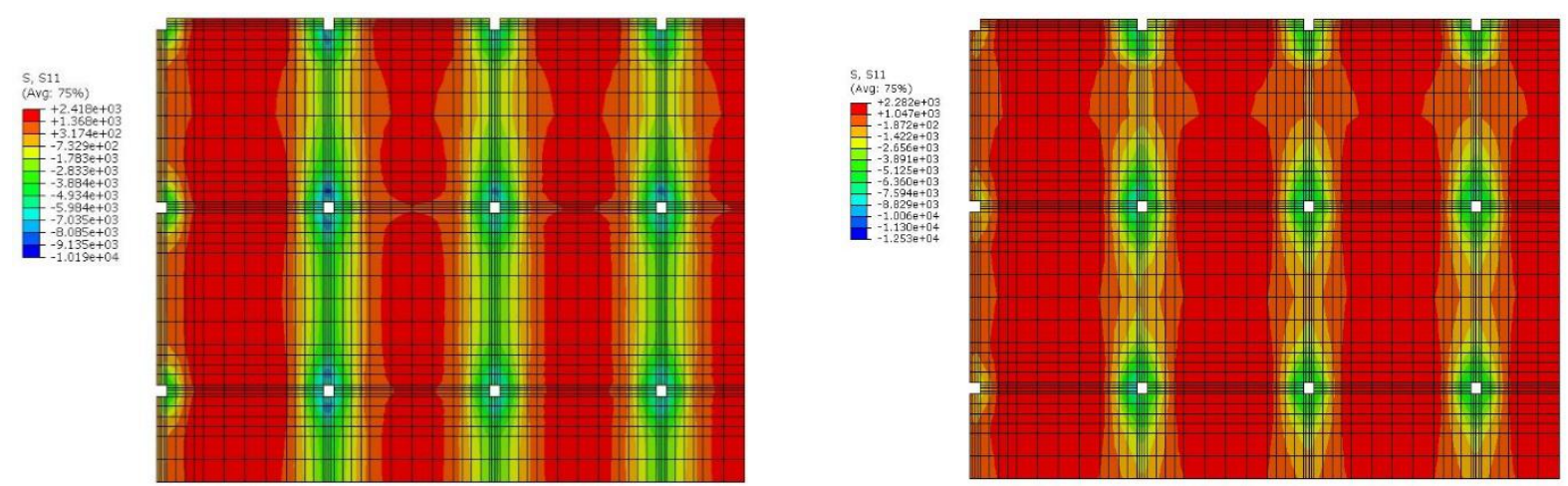

Fig. 11 Stresses in bottom surface in x-direction of ST1 model for cases A and DSh
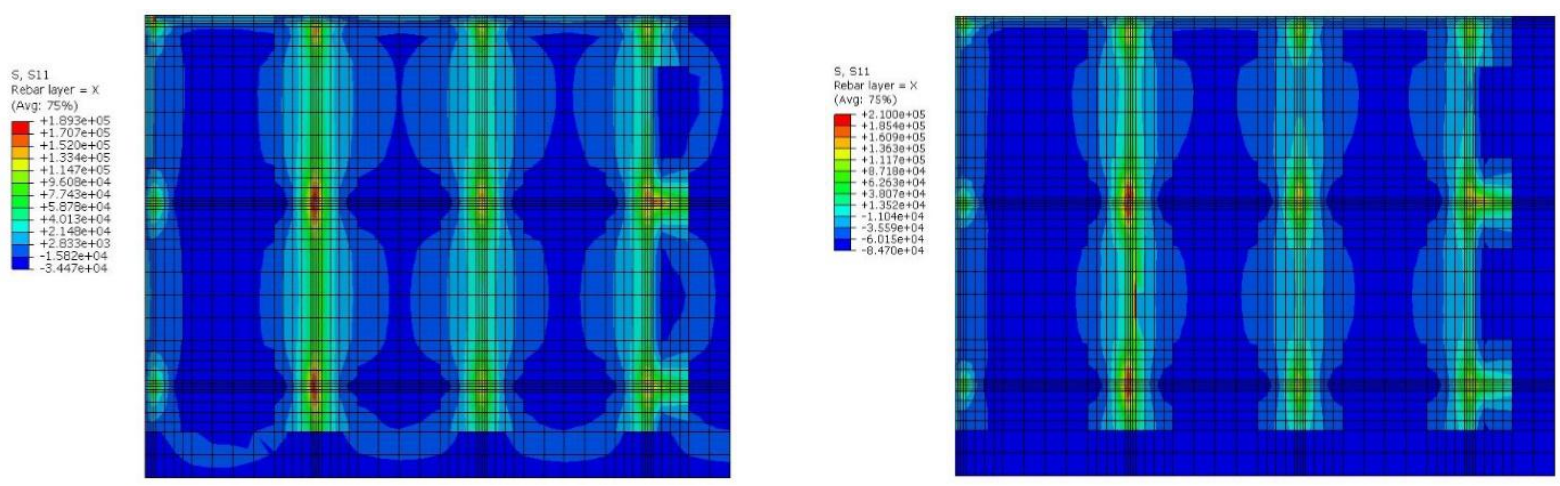

Fig. 12 Stresses in top reinforcement mesh in x-direction of ST1 model for cases A and DSh
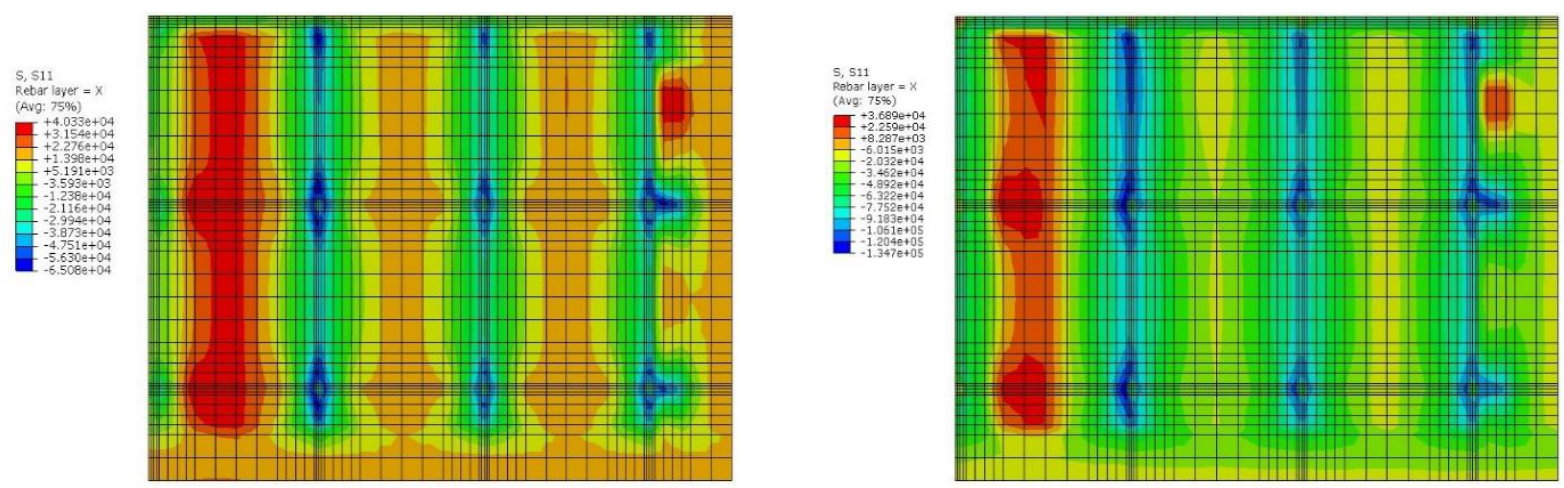

Fig. 13 Stresses in bottom reinforcement mesh in $\mathrm{x}$-direction of ST1 model for cases A and DSh

Table 1 Maximum deflection of ST1 model

\begin{tabular}{|l|c|c|c|c|c|c|c|c|c|c|c|}
\hline Case & $\mathrm{A}$ & $B$ & $C$ & $D$ & $E$ & $S h$ & $A S h$ & $B S h$ & $C S h$ & $D S h$ & $E S h$ \\
\hline $\begin{array}{l}\text { Max deflection, } \\
\mathrm{mm}\end{array}$ & 18 & 19 & 22 & 20 & 25 & 1 & 26 & 22 & 31 & 26 & 31 \\
\hline $\begin{array}{l}\text { Normalized to } \\
\text { Case A }\end{array}$ & 1.00 & 1.06 & 1.22 & 1.11 & 1.39 & .06 & 1.44 & 1.22 & 1.72 & 1.44 & 1.72 \\
\hline
\end{tabular}


Table 2 Maximum Tensile/Compressive concrete stress of ST1 model

\begin{tabular}{|l|c|c|c|c|}
\hline Case & $\begin{array}{l}\text { Tensile Stress, } \\
\mathrm{MPa}\end{array}$ & $\begin{array}{l}\text { Normalized } \\
\text { to Case A }\end{array}$ & $\begin{array}{l}\text { Compressive } \\
\text { Stress, MPa }\end{array}$ & $\begin{array}{l}\text { Normalized } \\
\text { to Case A }\end{array}$ \\
\hline$A$ & 2.42 & $100 \%$ & -10.02 & $100 \%$ \\
\hline$B$ & 2.22 & $92 \%$ & -11.26 & $112 \%$ \\
\hline$C$ & 2.38 & $98 \%$ & -11.77 & $117 \%$ \\
\hline$D$ & 2.32 & $96 \%$ & -9.43 & $94 \%$ \\
\hline$E$ & 2.40 & $99 \%$ & -11.15 & $111 \%$ \\
\hline$S h$ & 2.08 & $86 \%$ & -4.54 & $45 \%$ \\
\hline$A S h$ & 2.34 & $97 \%$ & -12.36 & $123 \%$ \\
\hline$B S h$ & 2.38 & $98 \%$ & -11.77 & $117 \%$ \\
\hline$C S h$ & 2.32 & $96 \%$ & -12.13 & $121 \%$ \\
\hline$D S h$ & 2.28 & $94 \%$ & -12.53 & $125 \%$ \\
\hline$E S h$ & 2.35 & $97 \%$ & -10.91 & $109 \%$ \\
\hline
\end{tabular}

Table 3 Maximum Tensile/Compressive reinforcement stress of ST1 model

\begin{tabular}{|l|c|c|c|c|}
\hline Case & $\begin{array}{l}\text { Tensile Stress, } \\
\text { MPa }\end{array}$ & $\begin{array}{l}\text { Normalized } \\
\text { to Case A }\end{array}$ & $\begin{array}{l}\text { Compressive } \\
\text { Stress, MPa }\end{array}$ & $\begin{array}{l}\text { Normalized } \\
\text { to Case A }\end{array}$ \\
\hline$A$ & 189 & $100 \%$ & -65 & $100 \%$ \\
\hline$B$ & 215 & $114 \%$ & -43 & $66 \%$ \\
\hline$C$ & 311 & $165 \%$ & -102 & $157 \%$ \\
\hline$D$ & 204 & $108 \%$ & -63 & $97 \%$ \\
\hline$E$ & 356 & $188 \%$ & -83 & $128 \%$ \\
\hline$S h$ & 43 & $23 \%$ & -74 & $114 \%$ \\
\hline$A S h$ & 360 & $190 \%$ & -135 & $208 \%$ \\
\hline$B S h$ & 311 & $165 \%$ & -102 & $157 \%$ \\
\hline$C S h$ & 344 & $182 \%$ & -168 & $258 \%$ \\
\hline$D S h$ & 210 & $111 \%$ & -134 & $206 \%$ \\
\hline$E S h$ & 360 & $190 \%$ & -136 & $209 \%$ \\
\hline
\end{tabular}

Table 4 Maximum Tensile/Compressive concrete stress in columns of ST1 model.

\begin{tabular}{|c|c|c|c|c|}
\hline Case & $\begin{array}{l}\text { Tensile Stress, } \\
\text { MPa }\end{array}$ & $\begin{array}{l}\text { Normalized } \\
\text { to Case A }\end{array}$ & $\begin{array}{l}\text { Compressive } \\
\text { Stress, MPa }\end{array}$ & $\begin{array}{l}\text { Normalized } \\
\text { to Case A }\end{array}$ \\
\hline$A$ & 2.41 & $100 \%$ & -16.37 & $100 \%$ \\
\hline$B$ & 2.19 & $91 \%$ & -17.92 & $109 \%$ \\
\hline$C$ & 2.36 & $98 \%$ & -14.47 & $88 \%$ \\
\hline$D$ & 2.38 & $99 \%$ & -15.06 & $92 \%$ \\
\hline$E$ & 2.36 & $98 \%$ & -17.43 & $106 \%$ \\
\hline$S h$ & 2.36 & $98 \%$ & -12.39 & $76 \%$ \\
\hline$A S h$ & 2.36 & $98 \%$ & -14.23 & $87 \%$ \\
\hline$B S h$ & 2.36 & $98 \%$ & -14.47 & $88 \%$ \\
\hline$C S h$ & 2.36 & $98 \%$ & -18.06 & $110 \%$ \\
\hline$D S h$ & 2.31 & $96 \%$ & -14.51 & $89 \%$ \\
\hline$E S h$ & 2.36 & $98 \%$ & -14.27 & $87 \%$ \\
\hline
\end{tabular}


Table 5 Maximum Tensile/Compressive reinforcement stress in columns of ST1 model.

\begin{tabular}{|c|c|c|c|c|}
\hline Case & $\begin{array}{l}\text { Tensile Stress, } \\
\mathrm{MPa}\end{array}$ & $\begin{array}{l}\text { Normalized } \\
\text { to Case A }\end{array}$ & $\begin{array}{l}\text { Compressive } \\
\text { Stress, MPa }\end{array}$ & $\begin{array}{l}\text { Normalized } \\
\text { to Case A }\end{array}$ \\
\hline$A$ & 192 & $100 \%$ & -115 & $100 \%$ \\
\hline$B$ & 244 & $127 \%$ & -109 & $95 \%$ \\
\hline$C$ & 218 & $114 \%$ & -111 & $97 \%$ \\
\hline$D$ & 211 & $110 \%$ & -114 & $99 \%$ \\
\hline$E$ & 257 & $134 \%$ & -113 & $98 \%$ \\
\hline$S h$ & 252 & $131 \%$ & -94 & $82 \%$ \\
\hline$A S h$ & 247 & $129 \%$ & -126 & $110 \%$ \\
\hline$B S h$ & 218 & $114 \%$ & -111 & $97 \%$ \\
\hline$C S h$ & 292 & $152 \%$ & -151 & $131 \%$ \\
\hline$D S h$ & 209 & $109 \%$ & -128 & $111 \%$ \\
\hline$E S h$ & 318 & $166 \%$ & -134 & $117 \%$ \\
\hline
\end{tabular}

From the obtained results the following remarks can be noticed:

1. For an accurate assessment of slab deflection, it is important to account for shrinkage.

2. The effect of temperature variation on concrete stresses is not significant; however, such effect becomes more pronounced when shrinkage is included in the analysis.

Stresses in slab reinforcement are very much affected by temperature and shrinkage, with the case of shrinkage and drop in temperature as the most critical. This leads to a conclusion that the effect of both temperature variation and shrinkage can be accommodated by additional reinforcement.

3. Shrinkage noticeably affects reinforcement stresses but not concrete stresses in columns.

\section{Raft Foundation - Two Cases Study}

Two similar models of raft foundation are presented here; one is supported directly on soil, RTS, and the other is supported on piles, RTP. The soil reaction on raft is represented by elastic spring of stiffness equal to $15000 \mathrm{kN} / \mathrm{m}^{2}$; assuming that the soil bearing capacity is $150 \mathrm{kN} / \mathrm{m}^{2}$. As for the piles, they are assumed to be end bearing piles and are introduced into the analysis as elastic springs with stiffness equal to $60000 \mathrm{kN} / \mathrm{m}$; the bearing capacity of pile is assumed to be $600 \mathrm{kN}$. Thus, the lateral resistance of piles is neglected in the analysis.

The two cases of raft foundation are analyzed under different temperature gradients and shrinkage as a drop-in temperature. The temperature gradients are assumed to vary only with the raft thickness and to be constant all over the raft surface.

Fig. 14 shows the geometry of the two rafts, which support square columns of similar dimensions of $1000 \times 1000 \mathrm{~mm}$. The thickness of either raft is $800 \mathrm{~mm}$. In the $\mathrm{x}$-direction there are fifteen spans, each is equal to $8.0 \mathrm{~m}$ from the centerline of columns in addition to an extension $0.50 \mathrm{~m}$ at every side, so the total raft length in the $\mathrm{x}$-direction is equal to $122.0 \mathrm{~m}$. In the $\mathrm{z}$-direction there are five spans, each is equal to $8.0 \mathrm{~m}$ from the centerline of columns in addition to an extension $0.50 \mathrm{~m}$ at every side, so the total raft length in the 
$\mathrm{z}$-direction is equal to $42 \mathrm{~m}$. For raft RTP, the piles are distributed every $2.0 \mathrm{~m}$ in the $\mathrm{x}-$ and z-directions.

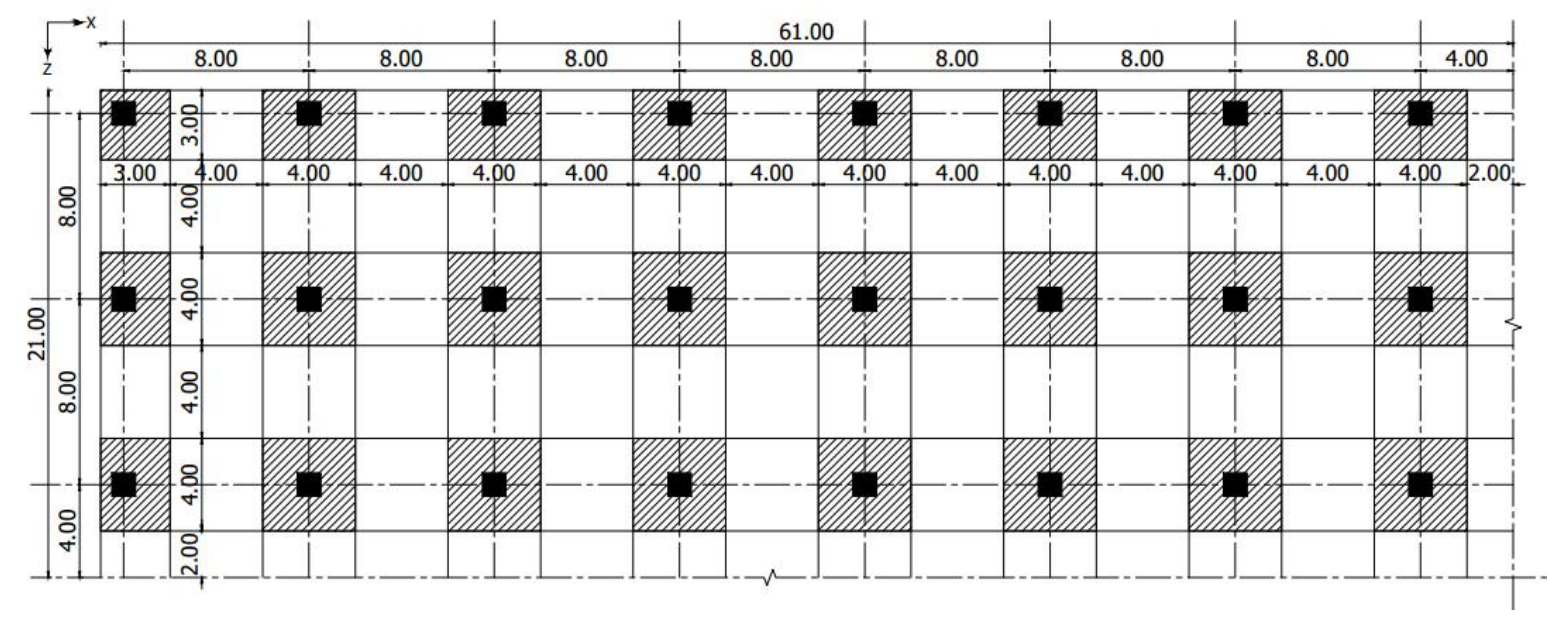

Fig. 14 One quarter dimensions of a rafts RTS and RTP

The rafts are divided into column and middle strips and are reinforced with top and bottom steel meshes of $\Phi 22-125 \mathrm{~mm}$ in the $\mathrm{x}$ - and z-directions in all zones except at the zones of intersections of column strips, which contain additional bottom reinforcement mesh of $\Phi 22-125 \mathrm{~mm}$ in the $\mathrm{x}$ - and $\mathrm{z}$-directions. The top and bottom concrete covers are assumed equal to $50 \mathrm{~mm}$ measured from the raft exterior fibers to the center of the rebars, where the reinforcement has been modeled as one surface layer.

Gravity loads comes from the building ten stories, so interior, edge and corner columns carrying loads equal to $12000 \mathrm{kN}, 6000 \mathrm{kN}$ and $3000 \mathrm{kN}$, respectively, applied at the mid heights of the columns. The columns own weights are neglected in the analysis. In addition to the gravity loads, the raft is assumed to carry thermal loads in the form of temperature gradients which are uniform, nonlinear gradients and shrinkage as a drop-in temperature as shown in Fig. 8. Herein also, there are eleven loading cases of nonlinear analyses, as given in the following:

Case $\boldsymbol{A}$ - vertical loads only.

Case $\boldsymbol{B}$ - vertical loads + uniform temperature gradient (T1).

Case $\boldsymbol{C}$ - vertical loads - uniform temperature gradient (T1).

Case $\boldsymbol{D}$ - vertical loads + nonlinear temperature gradient (T2).

Case $\boldsymbol{E}$ - vertical loads - nonlinear temperature gradient (T2).

Case $\boldsymbol{S h}$ - shrinkage as a drop-in temperature (T3) only.

Case ASh - case A + shrinkage (T3).

Case BSh - case B + shrinkage (T3).

Case $\boldsymbol{C S h}$ - case C + shrinkage (T3).

Case DSh - case D + shrinkage (T3).

Case ESh - case E + shrinkage (T3).

All columns are assumed to have zero moments at their mid heights. There are two axes of symmetry in the $\mathrm{x}$ - and z-directions (the boundary conditions along the line of symmetry in the $\mathrm{x}$-direction are $\mathrm{U}_{\mathrm{x}}, \mathrm{UR}_{\mathrm{y}}$ and $\mathrm{UR}_{\mathrm{z}}=0.0$ and the boundary conditions along 
the line of symmetry in the $z$-direction are $U_{z}, U_{x}$ and $U R_{y}=0.0$ ) so that one quarter model only is analyzed. For the raft RTS, the soil is represented by elastic springs of stiffness equal to $15.0 \mathrm{MN} / \mathrm{m}^{2}$. As for the raft RTP, the piles are accounted for as elastic springs of stiffness equal to $60.0 \mathrm{MN} / \mathrm{m}$. Abaqus/Explicit has been used for the analysis and modeling.

\section{Results and Comments}

Due to the large size of the obtained results, only some selected results of raft RTS are presented in Figs. 15 to 22 and of raft RTP in Figs. 23 to 30, respectively. From the obtained results, the values given in Tables 6 to 9 can be compared; the results are normalized to that of case A (case of gravity loads only).

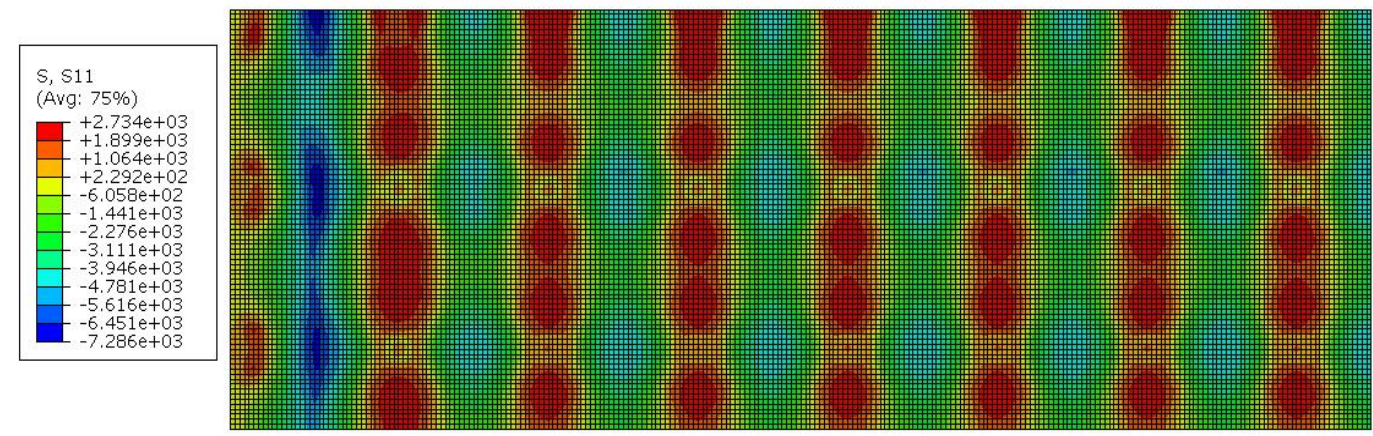

Fig. 15 Stresses in bottom surface in $\mathbf{x}$-direction of RTS model for Case A

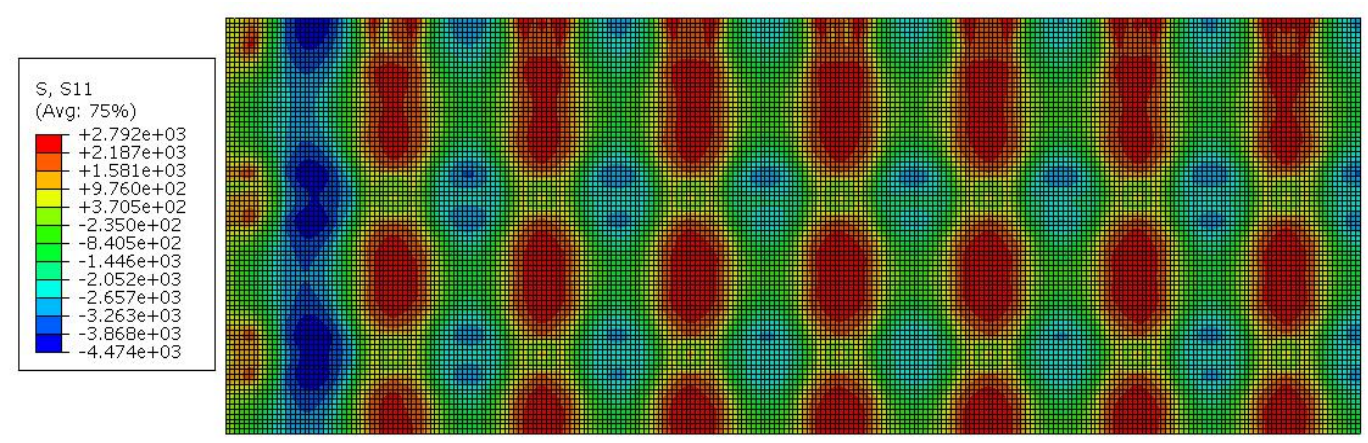

Fig. 16 Stresses in bottom surface in x-direction of RTS model for Case DSh

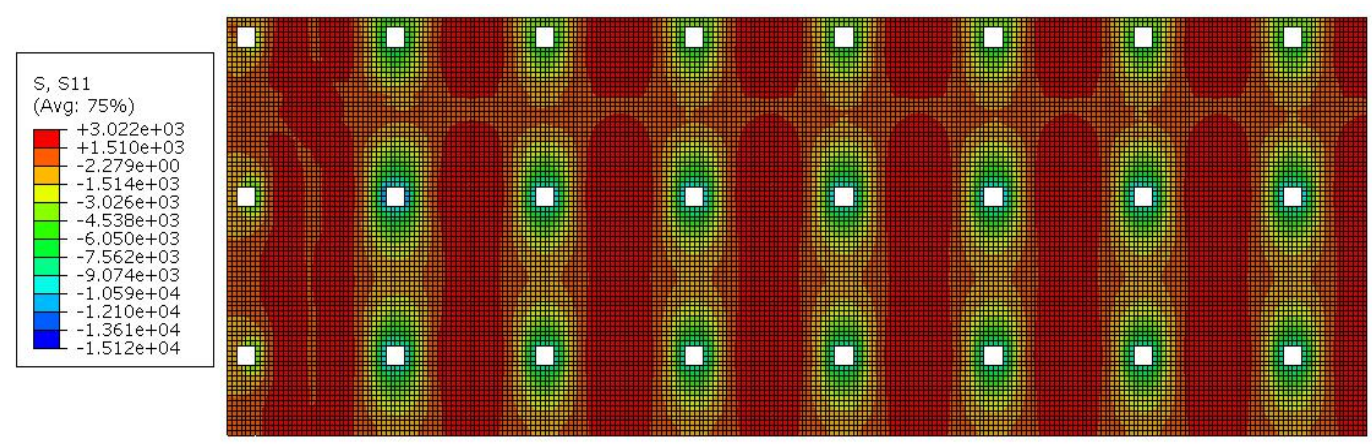

Fig. 17 Stresses in top surface in x-direction of RTS model for Case A 
Salah E. El-Metwally /et al /Engineering Research Journal 163 (September 2019) C1- C21

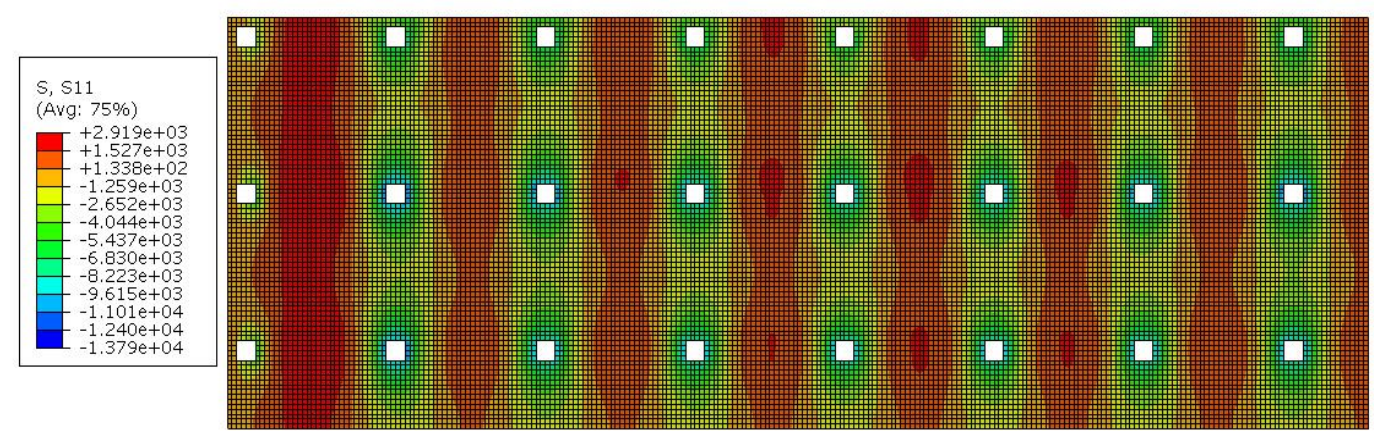

Fig. 18 Stresses in top surface in x-direction of RTS model for Case DSh

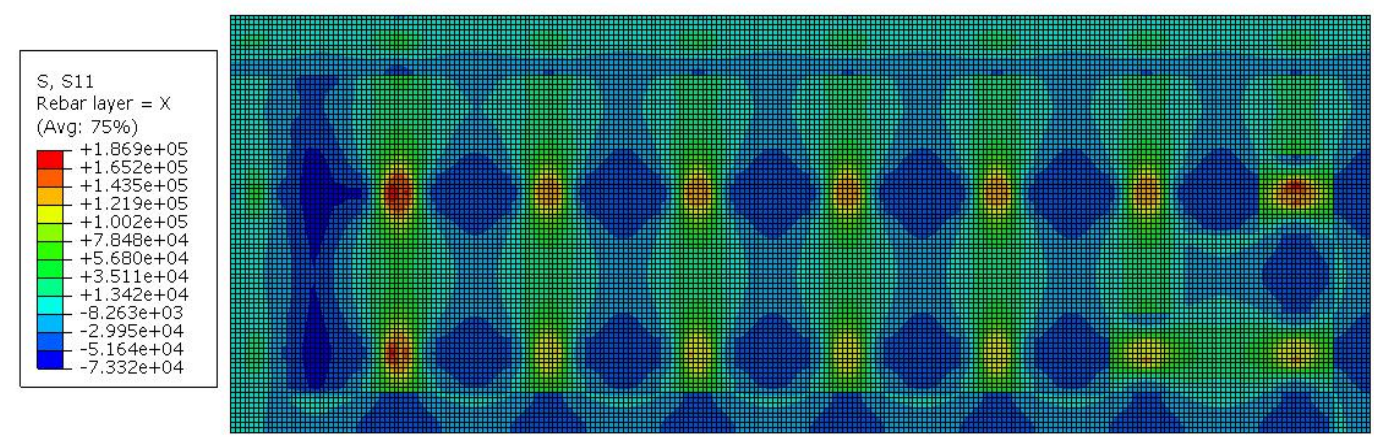

Fig. 19 Stresses in bottom reinforcement in x-direction of RTS model for Case A

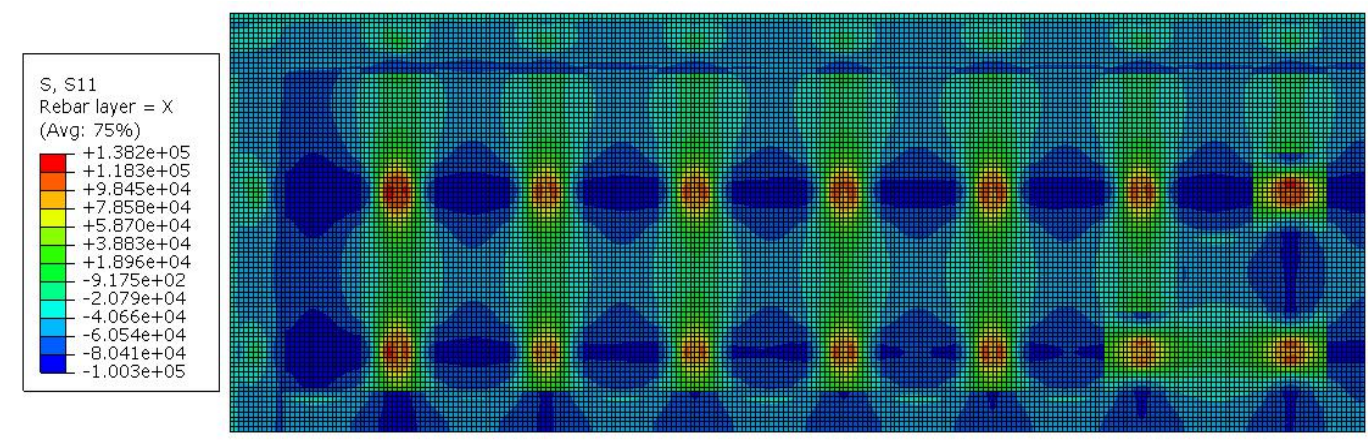

Fig. 20 Stresses in bottom reinforcement in x-direction of RTS model for Case DSh

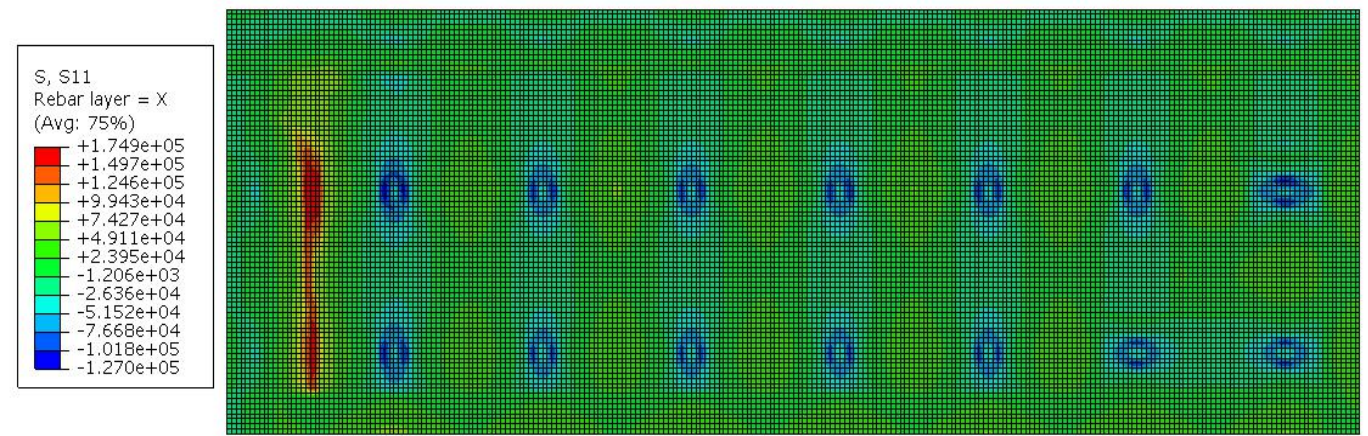

Fig. 21 Stress in top reinforcement in x-direction of RTS model for Case A 
Fig. 22 Stress in top reinforcement in x-direction of RTS model for Case DSh

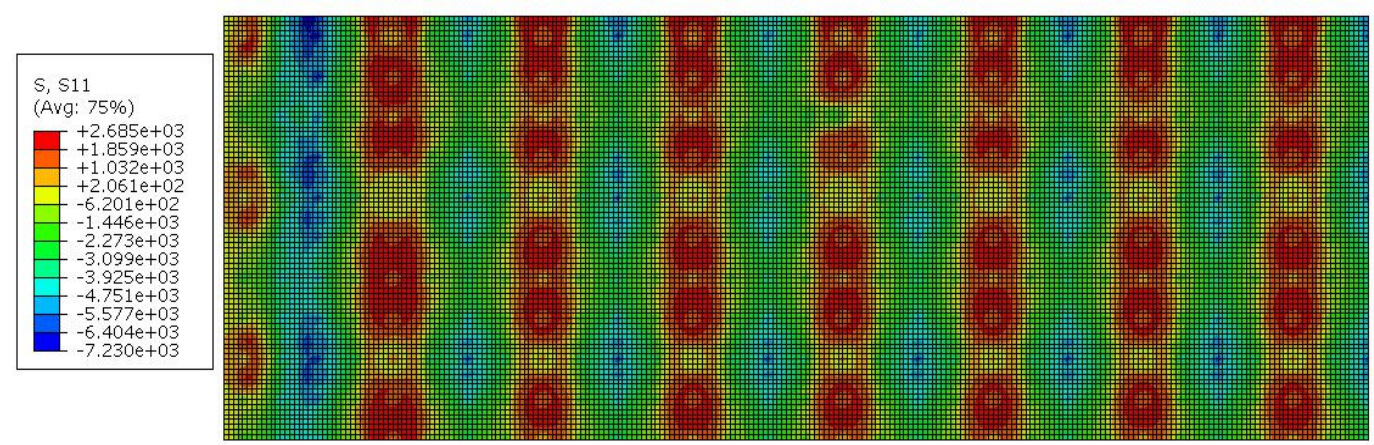

Fig. 23 Stress in bottom surface in x-direction of RTP model for Case A

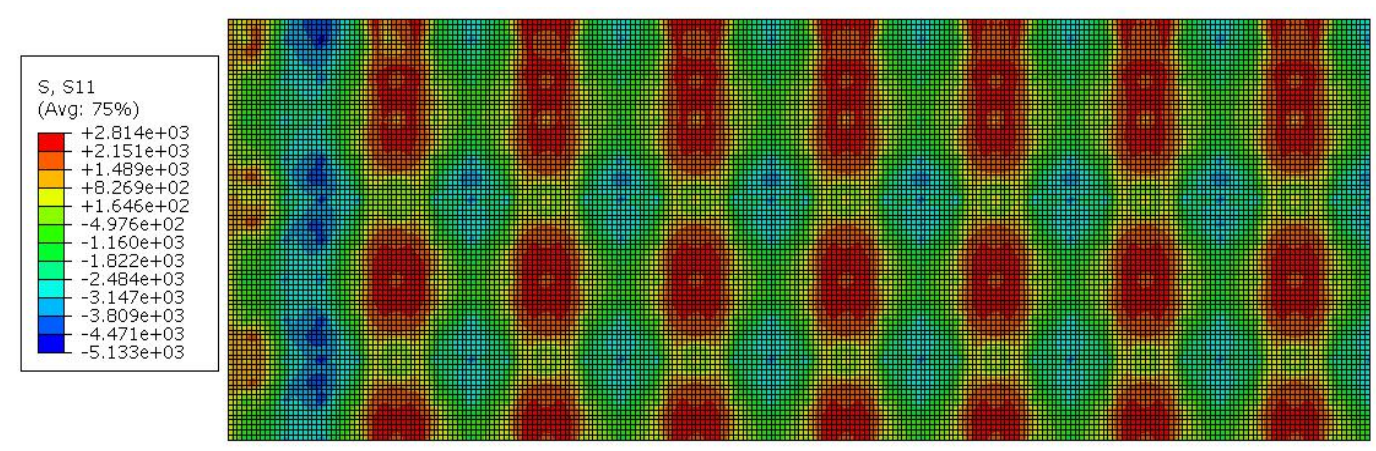

Fig. 24 Stress in bottom surface in x-direction of RTP model for Case DSh

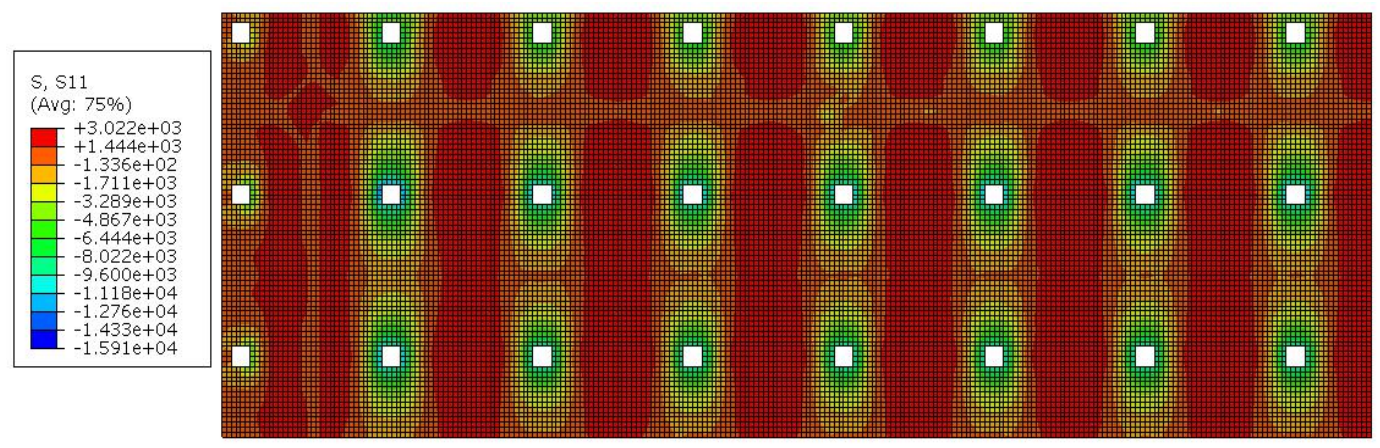

Fig. 25 Stress in top surface in x-direction of RTP model for Case A 
Salah E. El-Metwally /et al /Engineering Research Journal 163 (September 2019) C1- C21

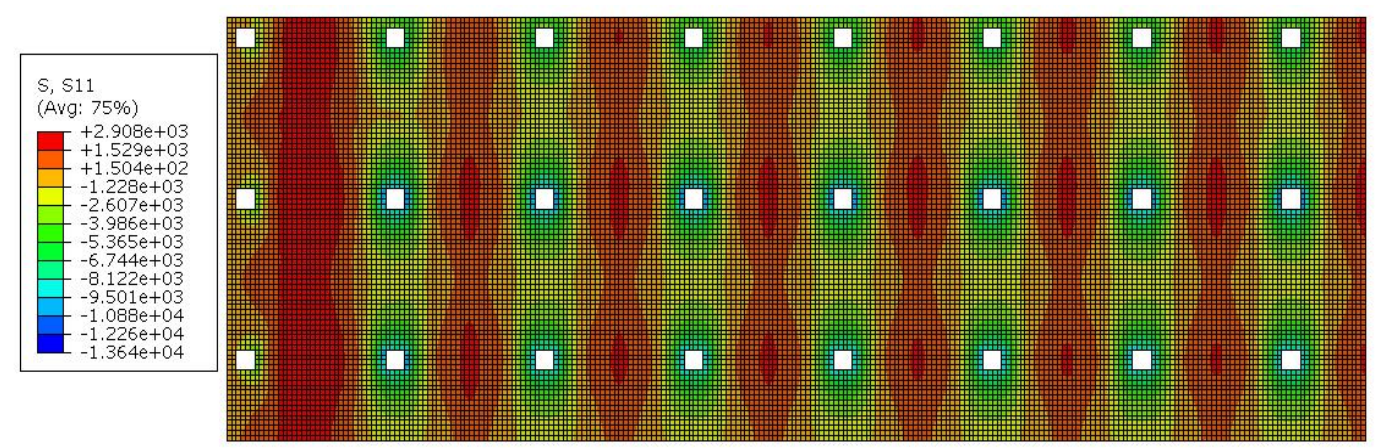

Fig. 26 Stress in top surface in x-direction of RTP model for Case DSh

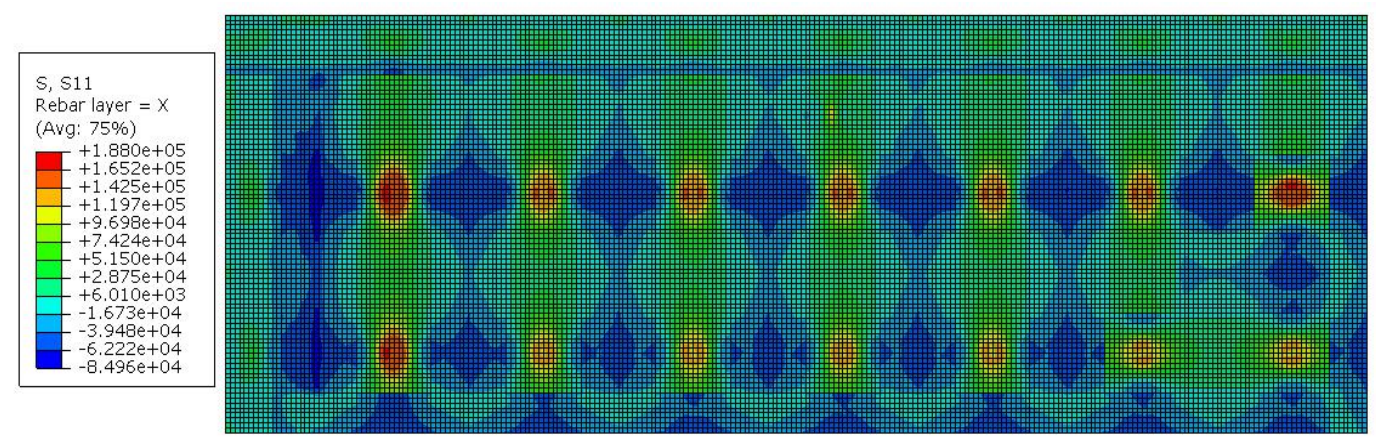

Fig. 27 Stress in bottom reinforcement in x-direction of RTP model for Case A

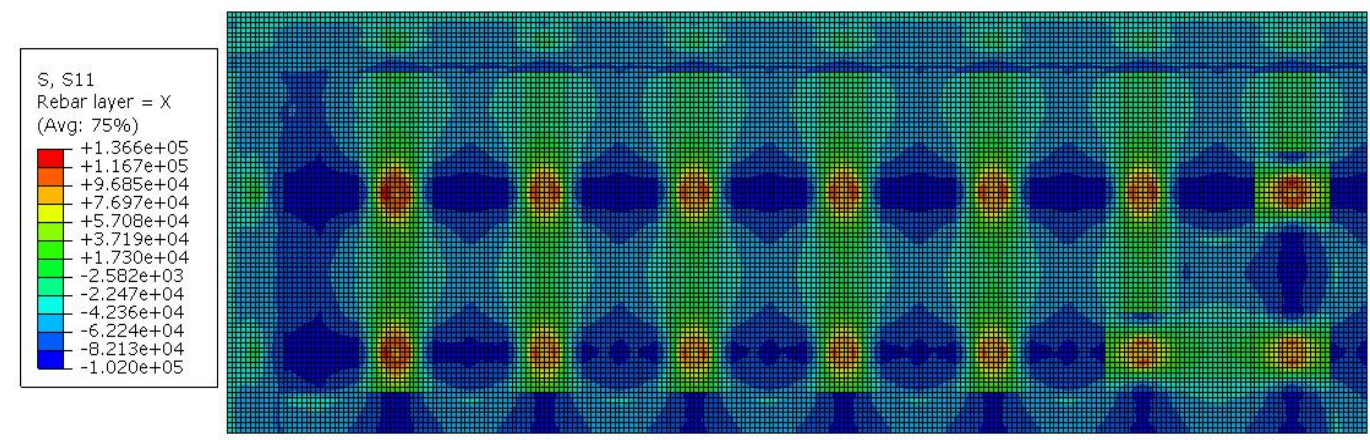

Fig. 28 Stress in bottom reinforcement in x-direction of RTP model for Case DSh

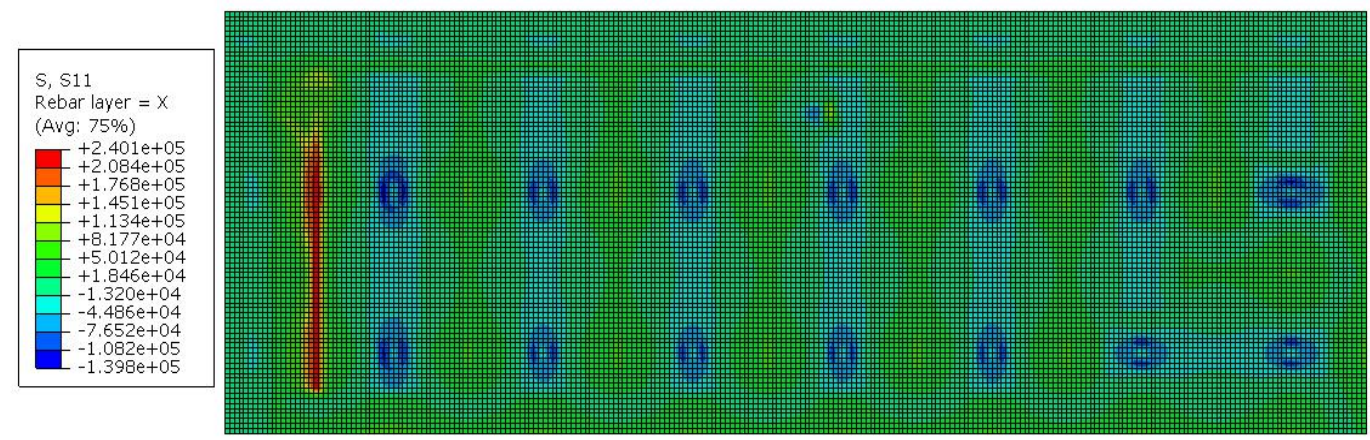

Fig. 29 Stress in top reinforcement in x-direction of RTP model for Case A 


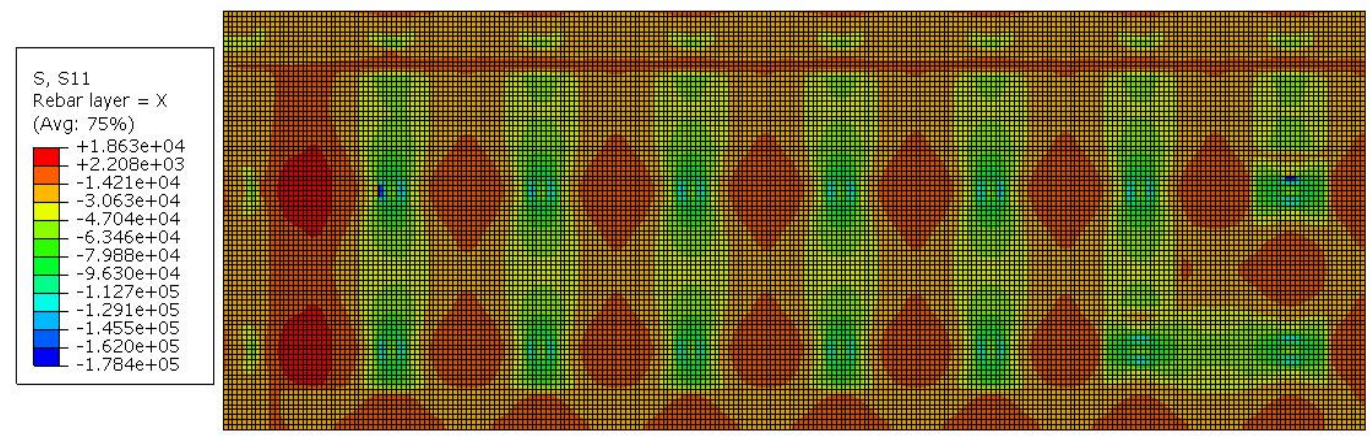

Fig. 30 Stress in top reinforcement in x-direction of RTP model for Case DSh

Table 6 Maximum Tensile/Compressive concrete stress of RTS model

\begin{tabular}{|l|c|c|c|c|}
\hline Case & $\begin{array}{l}\text { Tensile } \\
\text { Stress, MPa }\end{array}$ & $\begin{array}{l}\text { Normalized } \\
\text { to Case A }\end{array}$ & $\begin{array}{l}\text { Compressive } \\
\text { Stress, MPa }\end{array}$ & $\begin{array}{l}\text { Normalized } \\
\text { to Case A }\end{array}$ \\
\hline$A$ & 3.02 & $100 \%$ & -15.12 & $100 \%$ \\
\hline$B$ & 3.01 & $100 \%$ & -11.04 & $73 \%$ \\
\hline$C$ & 3.03 & $100 \%$ & -11.79 & $78 \%$ \\
\hline$D$ & 2.77 & $92 \%$ & -13.67 & $90 \%$ \\
\hline$E$ & 2.89 & $96 \%$ & -9.82 & $65 \%$ \\
\hline$S h$ & 1.06 & $35 \%$ & 0.14 & $-1 \%$ \\
\hline$A S h$ & 3.04 & $101 \%$ & -11.98 & $79 \%$ \\
\hline$B S h$ & 3.05 & $101 \%$ & -11.45 & $76 \%$ \\
\hline$C S h$ & 2.98 & $99 \%$ & -12.78 & $85 \%$ \\
\hline$D S h$ & 2.92 & $97 \%$ & -13.79 & $91 \%$ \\
\hline$E S h$ & 2.88 & $95 \%$ & -11.37 & $75 \%$ \\
\hline
\end{tabular}

Table 7 Maximum Tensile/Compressive reinforcement stress of RTS model

\begin{tabular}{|l|c|c|c|c|}
\hline Case & $\begin{array}{l}\text { Tensile } \\
\text { Stress, MPa }\end{array}$ & $\begin{array}{l}\text { Normalized } \\
\text { to Case A }\end{array}$ & $\begin{array}{l}\text { Compressive } \\
\text { Stress, MPa }\end{array}$ & $\begin{array}{l}\text { Normalized } \\
\text { to Case A }\end{array}$ \\
\hline$A$ & 187 & $100 \%$ & -127 & $100 \%$ \\
\hline$B$ & 151 & $81 \%$ & -51 & $40 \%$ \\
\hline$C$ & 107 & $57 \%$ & -129 & $102 \%$ \\
\hline$D$ & 166 & $89 \%$ & -89 & $70 \%$ \\
\hline$E$ & 132 & $71 \%$ & -98 & $77 \%$ \\
\hline$S h$ & -35 & $-19 \%$ & -45 & $35 \%$ \\
\hline$A S h$ & 112 & $60 \%$ & -142 & $112 \%$ \\
\hline$B S h$ & 106 & $57 \%$ & -102 & $80 \%$ \\
\hline$C S h$ & 165 & $88 \%$ & -194 & $153 \%$ \\
\hline$D S h$ & 138 & $74 \%$ & -143 & $113 \%$ \\
\hline$E S h$ & 151 & $81 \%$ & -159 & $125 \%$ \\
\hline
\end{tabular}


Table 8 Maximum Tensile/Compressive concrete stress of RTP model

\begin{tabular}{|l|c|c|c|c|}
\hline Case & $\begin{array}{l}\text { Tensile } \\
\text { Stress, MPa }\end{array}$ & $\begin{array}{l}\text { Normalized } \\
\text { to Case A }\end{array}$ & $\begin{array}{l}\text { Compressive } \\
\text { Stress, MPa }\end{array}$ & $\begin{array}{l}\text { Normalized } \\
\text { to Case A }\end{array}$ \\
\hline$A$ & 3.02 & $100 \%$ & -15.91 & $100 \%$ \\
\hline$B$ & 3.02 & $100 \%$ & -11.47 & $72 \%$ \\
\hline$C$ & 3.02 & $100 \%$ & -11.86 & $75 \%$ \\
\hline$D$ & 2.78 & $92 \%$ & -14.15 & $89 \%$ \\
\hline$E$ & 2.91 & $96 \%$ & -10.18 & $64 \%$ \\
\hline$S h$ & 1.18 & $39 \%$ & 0.11 & $-1 \%$ \\
\hline$A S h$ & 3.03 & $100 \%$ & -11.89 & $75 \%$ \\
\hline$B S h$ & 3.04 & $101 \%$ & -11.65 & $73 \%$ \\
\hline$C S h$ & 2.98 & $99 \%$ & -12.11 & $76 \%$ \\
\hline$D S h$ & 2.91 & $96 \%$ & -13.64 & $86 \%$ \\
\hline$E S h$ & 2.89 & $96 \%$ & -11.65 & $73 \%$ \\
\hline
\end{tabular}

Table 9 Maximum Tensile/Compressive reinforcement stress of RTP model

\begin{tabular}{|l|c|c|c|c|}
\hline Case & $\begin{array}{l}\text { Tensile } \\
\text { Stress, MPa }\end{array}$ & $\begin{array}{l}\text { Normalized } \\
\text { to Case A }\end{array}$ & $\begin{array}{l}\text { Compressive } \\
\text { Stress, MPa }\end{array}$ & $\begin{array}{l}\text { Normalized } \\
\text { to Case A }\end{array}$ \\
\hline$A$ & 240 & $100 \%$ & -140 & $100 \%$ \\
\hline$B$ & 146 & $61 \%$ & -53 & $38 \%$ \\
\hline$C$ & 110 & $46 \%$ & -130 & $93 \%$ \\
\hline$D$ & 162 & $68 \%$ & -94 & $67 \%$ \\
\hline$E$ & 154 & $64 \%$ & -99 & $71 \%$ \\
\hline$S h$ & -26 & $-11 \%$ & -47 & $34 \%$ \\
\hline$A S h$ & 107 & $45 \%$ & -145 & $104 \%$ \\
\hline$B S h$ & 120 & $50 \%$ & -103 & $74 \%$ \\
\hline$C S h$ & 166 & $69 \%$ & -193 & $138 \%$ \\
\hline$D S h$ & 137 & $57 \%$ & -178 & $127 \%$ \\
\hline$E S h$ & 205 & $85 \%$ & -161 & $115 \%$ \\
\hline
\end{tabular}

From the obtained results the following remarks can be noticed:

1. Temperature variation and shrinkage have no negative effect on concrete stresses in raft foundation.

2. Shrinkage and drop of temperature have significant effect on the stresses in reinforcement and therefore they be considered in the design process. This leads to a conclusion that the effect of both temperature variation and shrinkage can be accommodated by additional reinforcement.

\section{Conclusions}

In order to eliminate the need for expansion joints, this study has been carried out in order to investigate the role of shrinkage and temperature variation in the behavior of reinforced concrete flat plates and raft foundations. Though this investigation is essentially qualitative, the obtained results can guide to the following conclusions regarding the effect of the two factors.

1 Shrinkage and temperature variation have more significant effect on flat plate slabs than on rafts. 
2 The effect of both factors on concrete stresses is not critical in slabs and has no significance in rafts.

3 The stresses in steel reinforcement is noticeably affected in rafts and significantly affected in slabs by the two factors. This leads to the conclusion that the effect of both temperature variation and shrinkage can be accommodated by additional reinforcement.

4 In slabs, for an accurate assessment of deflection, it is important to account for both factors in the analysis.

5 For safe and economic design of long span structures, it is essential to perform nonlinear analysis.

\section{REFERENCES}

1 “ABAQUS 2016 Documentation” Dassault Systèmes Simulia Corp., Johnston, RI, USA.

2 ACI Committee 209, "Prediction of Creep, Shrinkage and Temperature Effects in Concrete Structures (ACI 209R-92, Reapproved 1997)," ACI Manual of Concrete Practice. American Concrete Institute, Farmington Hills, MI.

3 ACI Committee 224, "Control of Cracking in Concrete Structures (ACI 224R01)," ACI Manual of Concrete Practice. American Concrete Institute, Farmington Hills, MI, May 2001.

4 ACI Committee 318, "Building Code Requirements for Structural Concrete (ACI 318M-14) and Commentary." American Concrete Institute, Farmington Hills, MI, 2014.

5 Alih, S., and Khelil, A., "Tension Stiffening Parameter in Composite Concrete Reinforced with Inoxydable Steel: Laboratory and Finite Element Analysis," World Academy of Science, Engineering and Technology, International Journal of Civil, Environmental, Structural, Construction and Architectural Engineering, 6(2), pp. 147-152, 2012.

6 American Society of Civil Engineers, "Minimum Design Loads for Buildings and Other Structures," ASCE/SEI 7-10, Reston, Virginia, 2010.

7 Chaudhari, S. V., and Chakrabarti, M. A., "Modeling of Concrete for Nonlinear Analysis Using Finite Element Code ABAQUS," International Journal of Computer Applications, 44(7), pp. 14-18, 2012.

8 ECP 201, Egyptian Code for Calculating Loads and Forces in the Structural and Masonry Works, HBRC, Cairo, Egypt, 2012. 
9 ECP 203, Egyptian Code for Design and Construction of Concrete Structures, HBRC, Cairo, Egypt, 2017.

10 Ghali, A., Favre, R., and Elbadry, M., Concrete Structures: Stresses and Deformations, 3rd ed. Taylor \& Francis e-Library, 2006.

11 Nesset, J., and Skoglund, S., "Reinforced Concrete Subjected to Restraint Forces - Analytical and Non-Linear Finite Element Analysis.," Master's thesis, Chalmers University of Technology, Göteborg, Sweden, 2007.

12 Park. R., and Paulay, T., Reinforced Concrete Structures. John Wiley \& Sons, 1975.

13 Vecchio, F. J., "Nonlinear Analysis of Reinforced Concrete Frames Subjected to Thermal and Mechanical Loads," ACI Structural Journal, 84, pp. 492-501, 1987.

14 Wight, J. K., and Macgregor, J. G., Reinforced Concrete: Mechanics and Design, 6th Ed. New Jersey: Pearson Education, Inc., 2012.

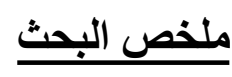

في هذه الدراسة، تم فحص تأثير الانكماش والتغير في درجة الحرارة على سلوك البلاطات الخرسانية المسطحة

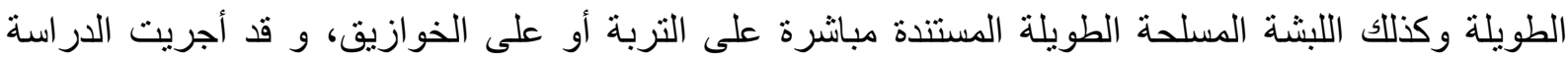

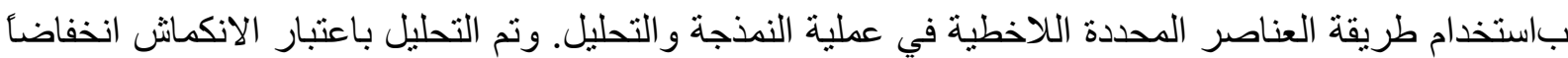

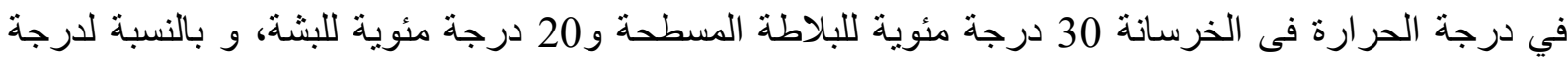
الحر ارة فقد تم تناول حالات اعتبار الثكل المنتظم واللاخطي للتغير في درجة الحرارة، ورئة ومع عمل كافة حالات

وتبين من خلال النتائج أن نمذجة المادة لاخطيا يلعب دورآ مهما فى استجابة المنشأ لتأثير الحرارة

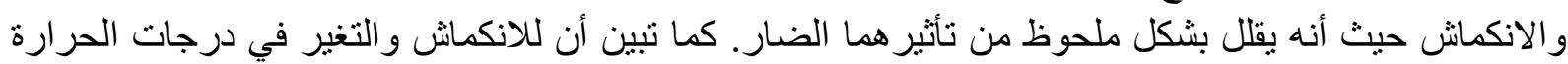

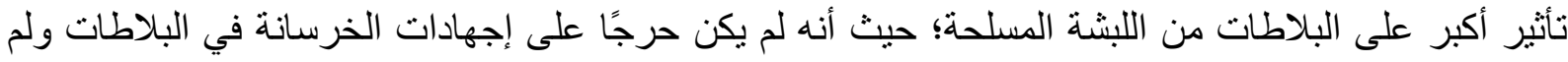

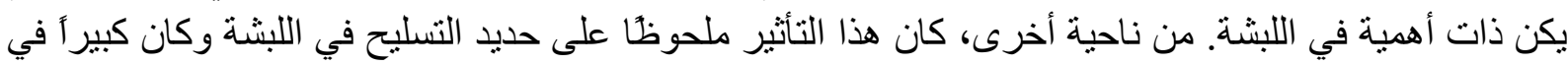

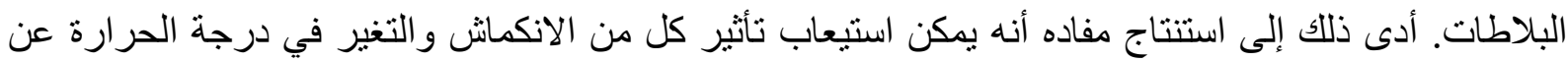

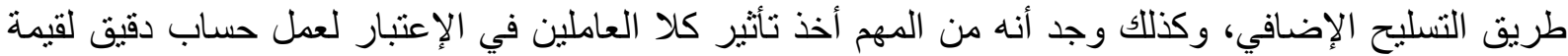
الترخيم فى البلاطات. 